\title{
The pure rotational spectrum of the $\mathrm{ZnBr}$ radical $\left(\mathrm{X}^{2} \Sigma^{+}\right)$: Trends in the zinc halide series
}

Cite as: J. Chem. Phys. 150, 034303 (2019); https://doi.org/10.1063/1.5079396

Submitted: 30 October 2018 . Accepted: 19 December 2018. Published Online: 16 January 2019

M. A. Burton, and L. M. Ziurys (D)

\section{ARTICLES YOU MAY BE INTERESTED IN}

Probing alkenoxy radical electronic structure using anion PEI spectroscopy

The Journal of Chemical Physics 150, 034302 (2019); https://doi.org/10.1063/1.5064795

A classical ride through a conical intersection

The Journal of Chemical Physics 150, 034301 (2019); https://doi.org/10.1063/1.5080399

Wavefunctions of macroscopic electron systems

The Journal of Chemical Physics 150, 030901 (2019); https://doi.org/10.1063/1.5050329

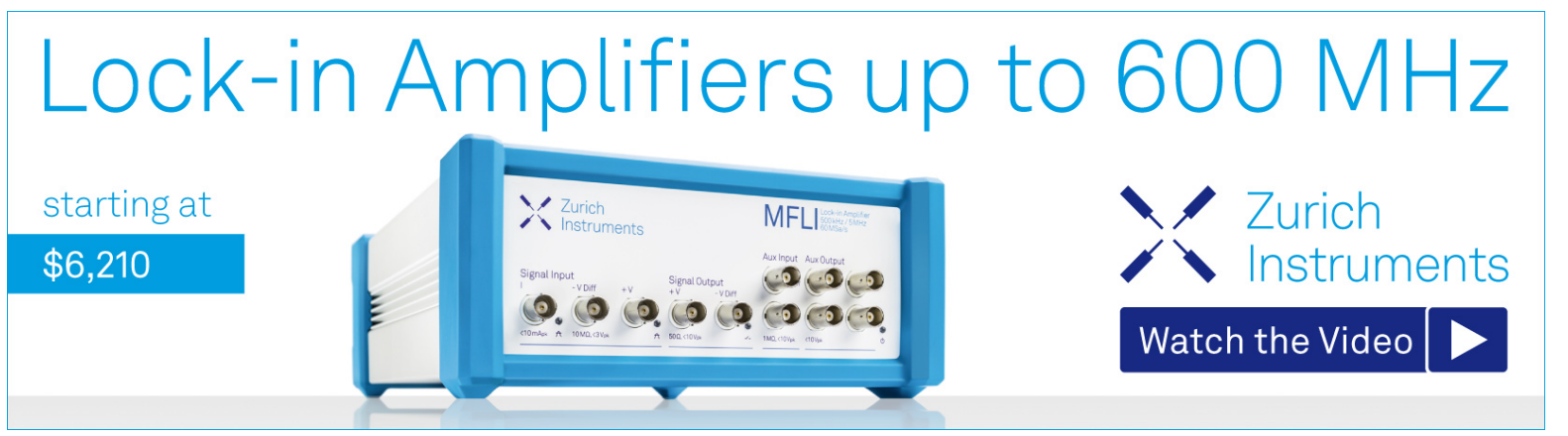

J. Chem. Phys. 150, 034303 (2019); https://doi.org/10.1063/1.5079396 


\title{
The pure rotational spectrum of the $\mathrm{ZnBr}$ radical $\left(X^{2} \Sigma^{+}\right)$: Trends in the zinc halide series
}

\author{
Cite as: J. Chem. Phys. 150, 034303 (2019); doi: 10.1063/1.5079396 \\ Submitted: 30 October 2018 - Accepted: 19 December 2018 • \\ Published Online: 16 January 2019
}

M. A. Burton and L. M. Ziurys $\mathbf{s}^{\mathrm{a})}$

\section{AFFILIATIONS}

Department of Chemistry and Biochemistry, Department of Astronomy, and Steward Observatory, University of Arizona, 1305 E. 4th Street, Tucson, Arizona 85719, USA

a)Email: Iziurys@email.arizona.edu. Telephone: 520-621-6525. Fax: 520-621-5554.

\begin{abstract}
The pure rotational spectrum of $\mathrm{ZnBr}\left(\mathrm{X}^{2} \Sigma^{+}\right)$has been recorded in the frequency range 259-310 GHz using millimeter-wave direct absorption techniques. This study is the first quantitative spectroscopic investigation of this free radical. $\mathrm{ZnBr}$ was synthesized in a DC discharge by the reaction of zinc vapor in argon with one of three reagents: $\mathrm{BrCH}_{3}, \mathrm{Br}_{2} \mathrm{CH}_{2}$, or $\mathrm{Br}_{2}$. Eight rotational transitions were measured for six isotopologues $\left({ }^{64} \mathrm{Zn}^{79} \mathrm{Br},{ }^{64} \mathrm{Zn}^{81} \mathrm{Br},{ }^{66} \mathrm{Zn}{ }^{79} \mathrm{Br},{ }^{66} \mathrm{Zn}^{81} \mathrm{Br},{ }^{68} \mathrm{Zn}^{79} \mathrm{Br}\right.$, and ${ }^{68} \mathrm{Zn}^{81} \mathrm{Br}$ ), all of which exhibited spin-rotation interactions. Furthermore, transitions originating in the $\mathrm{v}=1$ through 3 excited vibrational states were obtained for certain isotopologues. Five rotational transitions were also recorded for ${ }^{67} \mathrm{Zn}^{79} \mathrm{Br}$, in which hyperfine splittings were observed arising from the ${ }^{67} \mathrm{Zn}$ nucleus $(I=5 / 2)$. The spectra were analyzed using a Hund's case $\left(b_{\beta \mathrm{J}}\right)$ Hamiltonian, and rotational, spin-rotation, and ${ }^{67} \mathrm{Zn}$ magnetic hyperfine constants were determined. Equilibrium parameters were also derived for the ${ }^{64} \mathrm{Zn}^{79} \mathrm{Br},{ }^{64} \mathrm{Zn}^{81} \mathrm{Br},{ }^{66} \mathrm{Zn}^{79} \mathrm{Br}$, and ${ }^{66} \mathrm{Zn}^{81} \mathrm{Br}$ isotopologues, including the vibrational constant, $\omega_{\mathrm{e}}=286 \mathrm{~cm}^{-1}$. The equilibrium bond length was derived to be $r_{e}=2.26848(90) \AA$. Analysis of the ${ }^{67} \mathrm{Zn}$ hyperfine parameters suggest a decrease in ionic character in $\mathrm{ZnBr}$ from the other known zinc halides, $\mathrm{ZnF}$ and $\mathrm{ZnCl}$.
\end{abstract}

Published under license by AIP Publishing. https://doi.org/10.1063/1.5079396

\section{INTRODUCTION}

Simple zinc halide molecules have been widely used in chemistry for decades. ${ }^{\top}$ These species have played a major role in organic synthesis and catalysis. For example, $\mathrm{ZnCl}_{2}$ has been used to moderate aldol condensation reactions ${ }^{2}$ and in the selective reduction of many alkyl halides, ${ }^{3}$ while $\mathrm{ZnF}_{2}$ has been employed to generate other zinc synthetic agents. ${ }^{4} \mathrm{ZnBr}_{2}$ has been found to be an effective catalyst in the syntheses of styrene carbonate, ${ }^{5}$ epoxides, ${ }^{6}$ and ynones. ${ }^{7}$ In addition, this compound has a wide application in the construction of batteries, both for large-scale (flowing electrolyte, $50 \mathrm{~kW}-\mathrm{H}$ ) and small-scale (nonflow electrolyte, $<5 \mathrm{~kW}-\mathrm{H}$ ) systems..$^{8-12}$

Because of these applications, there have been various studies attempting to characterize the fundamental properties of simple zinc halide systems, both experimentally and theoretically. Various electronic transitions have been recorded for $\mathrm{ZnCl}$, including the $\mathrm{A}^{2} \Pi-\mathrm{X}^{2} \Sigma, \mathrm{C}^{2} \Pi-\mathrm{X}^{2} \Sigma$ and
$\mathrm{E}^{2} \Sigma-\mathrm{X}^{2} \Sigma$ bands, establishing vibrational constants for ground and several excited states. ${ }^{13,14} \mathrm{ZnCl}$ has also been investigated via pure rotational spectroscopy in its $\mathrm{X}^{2} \Sigma$ state $^{15}$ and has been the focus of theoretical studies ${ }^{16,17}$ in which the dipole moment, dissociation energies, and other molecular properties were computed. $\mathrm{ZnF}$ has been the subject of both $\mathrm{ESR} /$ matrix $^{18}$ and pure rotational measurements, ${ }^{19}$ as well as theory. ${ }^{16}$ The spectroscopic constants of $\mathrm{ZnCl}$ and $\mathrm{ZnF}$ are now well-determined, including the ${ }^{67} \mathrm{Zn}$ magnetic hyperfine parameters.

In contrast, little spectroscopic data currently exists for the next member in the series: $\mathrm{ZnBr}$. There were various reports of the observation of electronic bands due to this molecule, as summarized by Gosavi et al., ${ }^{20}$ who conducted the first quantitative analysis of the ${ }^{2} \Pi-X^{2} \Sigma$ transition of $\mathrm{ZnBr}$. These authors established an equilibrium vibrational frequency $\left(\omega_{\mathrm{e}}\right)$ for the ${ }^{2} \Pi$ and $\mathrm{X}^{2} \Sigma$ states of 358 and $319 \mathrm{~cm}^{-1}$, respectively. A Raman spectrum was subsequently measured for this radical in a krypton matrix, also establishing the 
ground state vibrational frequency of $198 \mathrm{~cm}^{-1} \cdot{ }^{21}$ The disagreement between the matrix and gas phase vibrational values prompted computational studies of $\mathrm{ZnBr}$ by Bowmaker and Schwerdtfeger ${ }^{22}$ and Liao et al.; ${ }^{23}$ these authors derived a fundamental vibrational frequency near $\sim 230 \mathrm{~cm}^{-1}$, in disagreement with both experimental results. Very recently, further theoretical studies of $\mathrm{ZnBr}$ were performed using ab initio complete active space self-consistent field (CASSCF) methods by Elmoussaoui and Korek $^{24}$ and Elmoussaoui et al. ${ }^{25}$ These studies produced the most reliable theoretical parameters for zinc bromide to date, estimating $\omega_{\mathrm{e}} \sim 267 \mathrm{~cm}^{-1}$ and $\mathrm{r}_{\mathrm{e}} \sim 2.341 \AA$. Elmoussaoui and Korek $^{24}$ also established the presence of 19 low-lying doublet and quartet states for the radical. Despite the computational interest, however, no spectroscopic work has been further conducted for $\mathrm{ZnBr}$.

Here we present the first high-resolution spectroscopic study of $\mathrm{ZnBr}$ in its $\mathrm{X}^{2} \Sigma^{+}$state. The millimeter-wave spectrum of this free radical was recorded in the frequency range 259-310 GHz using direct absorption methods. Seven different isotopologues were studied in their $\mathrm{v}=0$ state, and several in the $\mathrm{v}=1-3$ excited states. Rotation and spin-rotation constants were determined for these species, as well as the ${ }^{67} \mathrm{Zn}$ magnetic hyperfine parameters for ${ }^{67} \mathrm{Zn}^{79} \mathrm{Br}$. Equilibrium parameters were also established for the four most abundant isotopologues. This work significantly extends the characterization of $3 d$-bromide species, which has been limited to microwave/millimeter-wave measurements of $\mathrm{ScBr},{ }^{26} \mathrm{CuBr},{ }^{27,28}$ and $\mathrm{NiBr},{ }^{29}$ and rotationally resolved optical work for $\mathrm{ScBr},{ }^{30} \mathrm{TiBr},{ }^{31}$ and $\mathrm{NiBr} .{ }^{32}$ It also allows direct comparison of chemical trends within the halide group, complementing our previous studies of $\mathrm{ZnCl}$ and $\mathrm{ZnF}$. In this paper, we present our results, spectroscopic analysis, and interpretation of molecular parameters for $\mathrm{ZnBr}$.

\section{EXPERIMENTAL}

The pure rotational spectra of $\mathrm{ZnBr}\left(\mathrm{X}^{2} \Sigma^{+}\right)$were recorded using one of the direct absorption spectrometers of the Ziurys group. $^{33}$ Briefly, the radiation source, covering the range 65-850 GHz, consists of various Gunn oscillator and varactor multiplier combinations. One linear polarization is produced by the source. The radiation is launched from a feedhorn/lens assembly, passed through a polarizing grid, and is directed quasi-optically into a $1 / 2 \mathrm{~m}$ long cylindrical reaction chamber, sealed at both ends with Teflon lenses. A Broidatype oven is attached to the cell for metal vaporization. A rooftop mirror, located at the end of the cell, reflects the radiation back through the chamber, rotating the polarization by $90^{\circ}$. The grid then reflects the radiation into the detector, a helium-cooled, hot electron bolometer. Phasesensitive detection is implemented by frequency modulation of the source. Signals are collected at twice the modulation frequency, which produces a second-derivative line shape.

$\mathrm{ZnBr}$ was synthesized in a DC discharge by the reaction of zinc vapor, produced by the Broida-type oven, with either $\mathrm{BrCH}_{3}, \mathrm{Br}_{2} \mathrm{CH}_{2}$, or $\mathrm{Br}_{2}$ diluted in an argon carrier gas. Less than 1 mTorr of reactant gas was flowed over top the oven and mixed with $\sim 15$ mTorr of argon, flowed up from the bottom of the oven, to entrain the metal vapor. Increasing the amount of reactant gas reduced the signals, particularly with $\mathrm{Br}_{2}$. Additional argon ( 20 mTorr) was also streamed around the two Teflon lenses to prevent coating by the metal vapor. A DC discharge current of $0.85-1 \mathrm{amp}$ was optimal for molecule production. The zinc and bromine isotopologues of $\mathrm{ZnBr}$ were observed in their natural abundances of ${ }^{64} \mathrm{Zn}:{ }^{66} \mathrm{Zn}:{ }^{67} \mathrm{Zn}:{ }^{68} \mathrm{Zn}=48.6: 27.9: 4.1: 18.8$ and ${ }^{79} \mathrm{Br}:{ }^{81} \mathrm{Br}=50.7: 49.3$.

Transition frequencies were determined from $5 \mathrm{MHz}$ wide scans, centered on individual lines. Typically, 10 averaged scans ( 5 ascending in frequency, 5 descending) were required for an adequate signal-to-noise ratio. About 20-40 scan averages were needed to measure the ${ }^{67} \mathrm{Zn}$ hyperfine lines. The estimated experimental accuracy is $\pm 50 \mathrm{kHz}$.

\section{RESULTS}

The spectrum of $\mathrm{ZnBr}$ was found in the course of searching for another molecule. Scanning a $30 \mathrm{GHz}$ region while reacting zinc vapor with $\mathrm{BrCH}_{3}$ resulted in the appearance of a series of doublets, varying in intensity, with a doublet separation of about $120 \mathrm{MHz}$. The lines were found to require both zinc and bromomethane. The strongest harmonic pattern yielded a rotational constant within $\sim 200 \mathrm{MHz}$ of that predicted by theory ${ }^{24}$ for $\mathrm{ZnBr}$. The set of harmonic doublets lying highest in frequency in the pattern were assigned to ${ }^{64} \mathrm{Zn}^{79} \mathrm{Br}$, the least massive isotopologue. The heavier species, resulting from all combinations of ${ }^{64} \mathrm{Zn},{ }^{66} \mathrm{Zn}$, and ${ }^{68} \mathrm{Zn}$, with ${ }^{79} \mathrm{Br}$

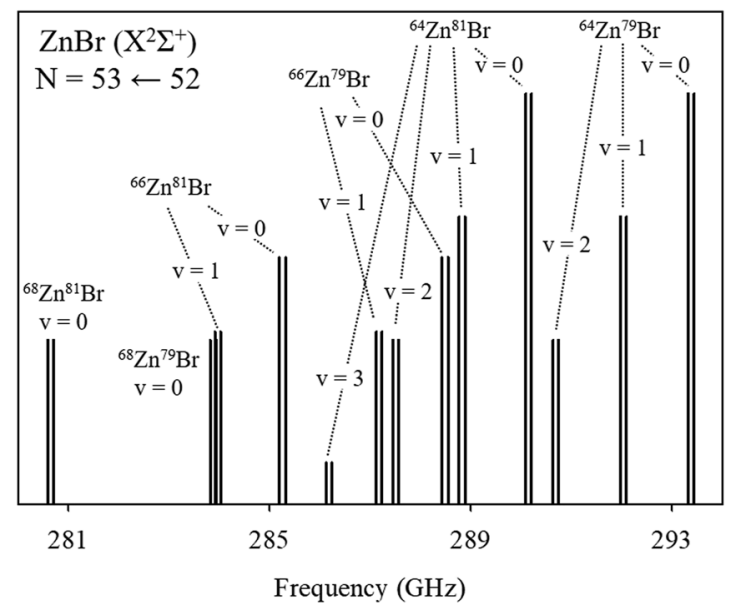

FIG. 1. Stick diagram illustrating the pattern of the $N=53 \leftarrow 52$ rotational transition for ${ }^{64} \mathrm{Zn}^{79} \mathrm{Br},{ }^{64} \mathrm{Zn}^{81} \mathrm{Br},{ }^{66} \mathrm{Zn}^{79} \mathrm{Br},{ }^{66} \mathrm{Zn}^{81} \mathrm{Br}$, ${ }^{68} \mathrm{Zn}^{79} \mathrm{Br}$, and ${ }^{68} \mathrm{Zn}{ }^{81} \mathrm{Br}$ in the $v=0-3$ states, showing the spin-rotation doublets. For clarity, transitions for ${ }^{67} \mathrm{Zn}^{79} \mathrm{Br}$ have been omitted. Approximate observed intensities are given, which reflect the natural abundances for zinc-64, 66, 68 and bromine-79, 81, and the increased energies of the vibrational states. 


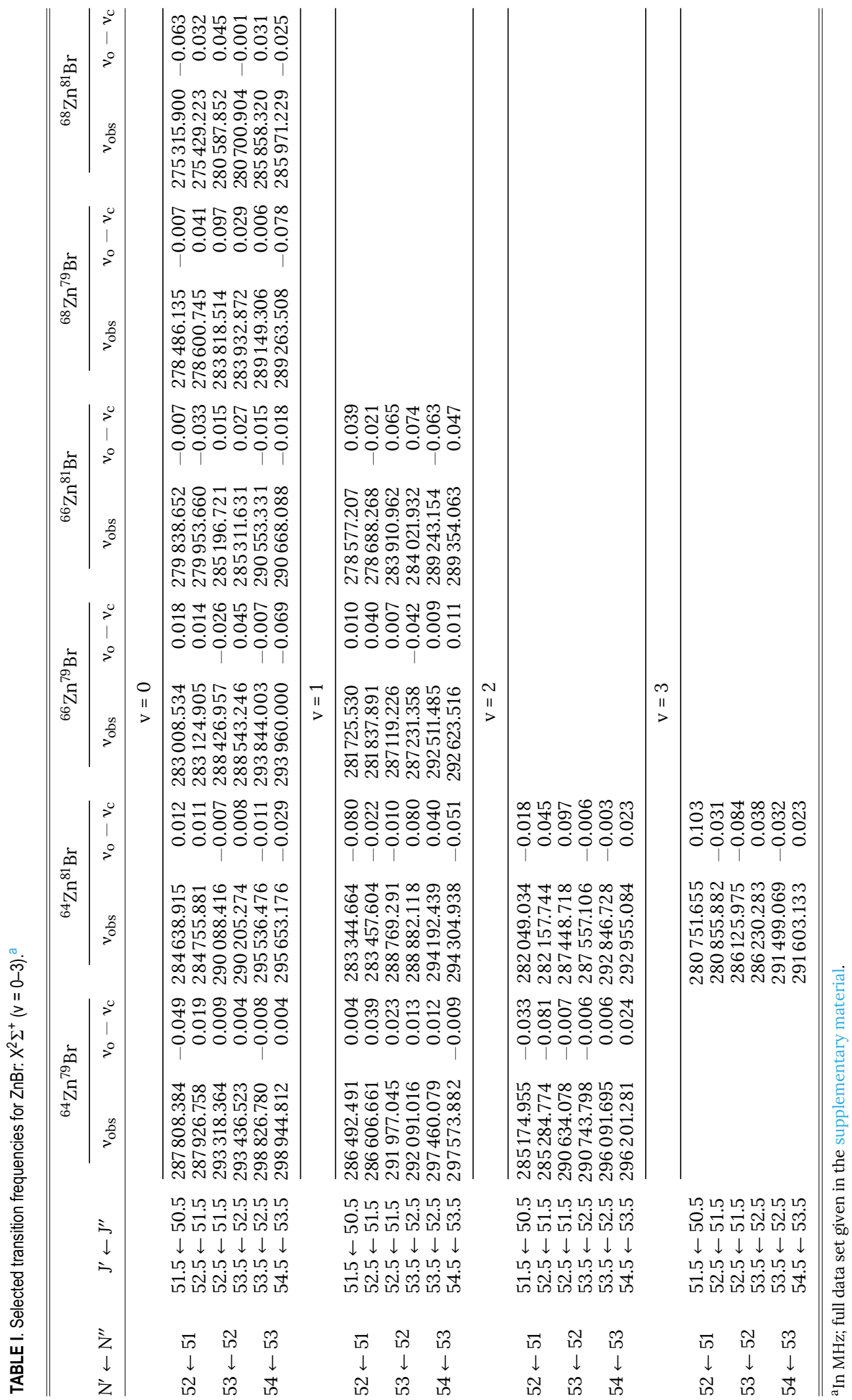




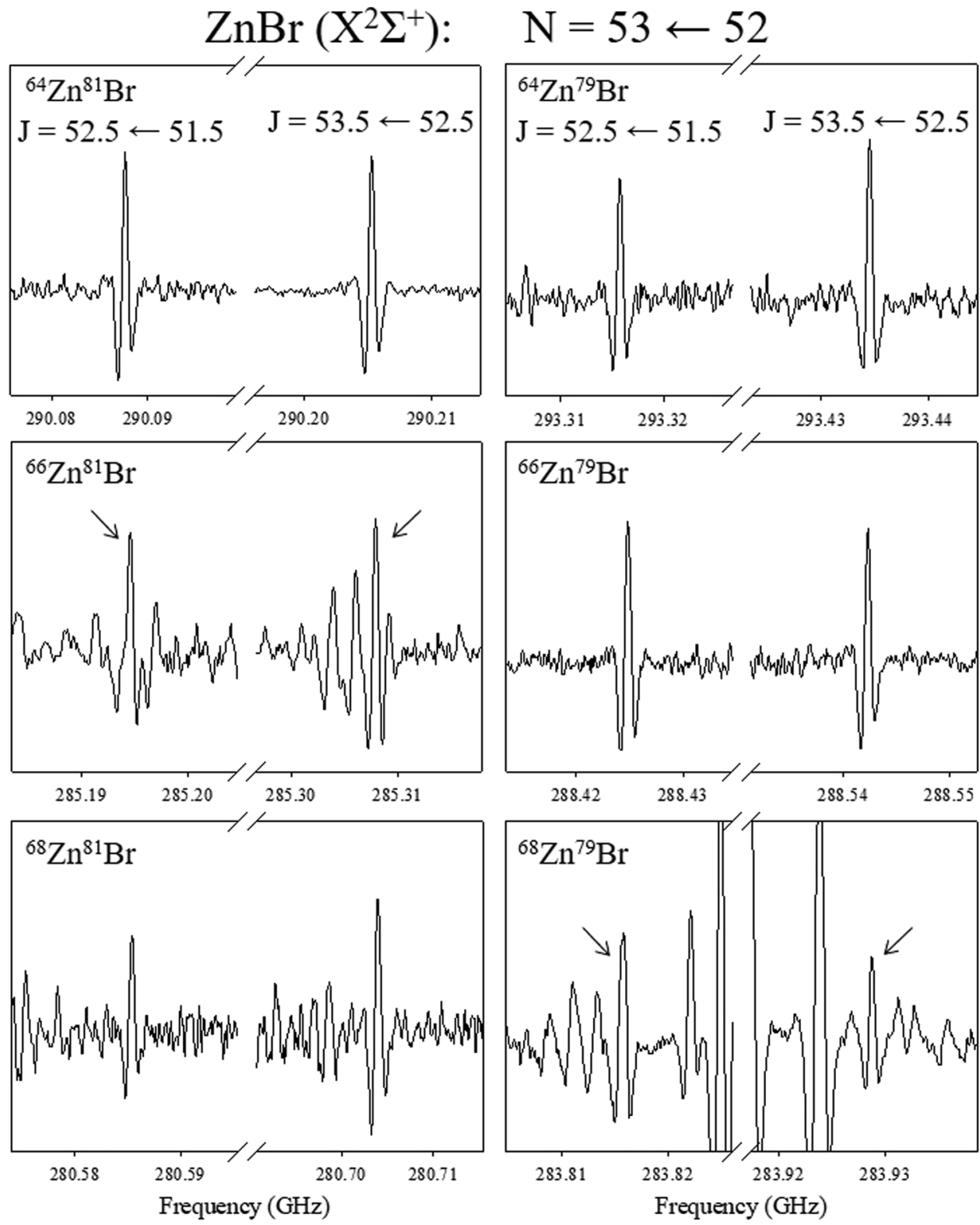

FIG. 2. Individual spectra of the $N=53 \leftarrow 52$ rotational transition $(v=0)$ for six $\mathrm{ZnBr}\left(\mathrm{X}^{2} \Sigma^{+}\right)$isotopologues measured in the range $280-293 \mathrm{GHz}$. The top panels show ${ }^{64} \mathrm{Zn}{ }^{81} \mathrm{Br}$ and ${ }^{64} \mathrm{Zn}{ }^{79} \mathrm{Br}$. the middle panels are ${ }^{66} \mathrm{Zn}^{81} \mathrm{Br}$ and ${ }^{66} \mathrm{Zn}{ }^{79} \mathrm{Br}$, and the lower panels present ${ }^{68} \mathrm{Zn}{ }^{81} \mathrm{Br}$ and ${ }^{68} \mathrm{Zn}{ }^{79} \mathrm{Br}$. Each spectrum contains a frequency break in order to show the respective spin-rotation doublets, labeled by $J=52.5 \leftarrow 51.5$ and $J=53.5 \leftarrow 52.5$. The arrows indicate the doublets when contaminating features are present. Each spectrum was created from two, $70 \mathrm{~s}, 110 \mathrm{MHz}$-wide scans, which were truncated and spliced to produce the shown figures. and ${ }^{81} \mathrm{Br}$ were then located by simple mass-scaling of the rotational constants. The remaining doublets were found to exhibit patterns with uniformly decreasing intensities that readily identified them as arising from excited vibrational states. Thereafter, the ${ }^{67} \mathrm{Zn}^{79} \mathrm{Br}$ species was found, which exhibited a complex hyperfine pattern due to the ${ }^{67} \mathrm{Zn}$ nuclear spin of $I=5 / 2$. In total, 255 lines were measured between seven isotopologues and three vibrational states. The data clearly indicate that the ground state for $\mathrm{ZnBr}$ is ${ }^{2} \Sigma^{+}$, as found for $\mathrm{ZnF}^{19}$ and $\mathrm{ZnCl}^{15}$ There was no evidence of bromine hyperfine splitting in the spectra; both bromine nuclei have spins of $I=3 / 2$.
Figure 1 illustrates the spectral pattern observed for the $\mathrm{N}=53 \leftarrow 52$ rotational transition of $\mathrm{ZnBr}\left(\mathrm{X}^{2} \Sigma^{+}\right)$. This stick spectrum shows the lines originating from ${ }^{64} \mathrm{Zn}^{79} \mathrm{Br}$, ${ }^{64} \mathrm{Zn}^{81} \mathrm{Br},{ }^{66} \mathrm{Zn}^{79} \mathrm{Br},{ }^{66} \mathrm{Zn}^{81} \mathrm{Br},{ }^{68} \mathrm{Zn}^{79} \mathrm{Br}$, and ${ }^{68} \mathrm{Zn}^{81} \mathrm{Br}$; for clarity, ${ }^{67} \mathrm{Zn}^{79} \mathrm{Br}$ was not included. The vibrational satellite lines identified in the data are also indicated, which varied with isotopologue.

Select transition frequencies are presented in Table I for ${ }^{64} \mathrm{Zn}^{79} \mathrm{Br},{ }^{64} \mathrm{Zn}^{81} \mathrm{Br},{ }^{66} \mathrm{Zn}^{79} \mathrm{Br},{ }^{66} \mathrm{Zn}^{81} \mathrm{Br},{ }^{68} \mathrm{Zn}^{79} \mathrm{Br}$, and ${ }^{68} \mathrm{Zn}^{81} \mathrm{Br}$ for the $\mathrm{v}=0$ and $\mathrm{v}=1-3$ vibrational states. A complete set is available in the supplementary material. The spin-rotation doublets, labeled by quantum number $\mathrm{J}$, where $\mathbf{J}=\mathbf{N}+\mathbf{S}$, were 
measured for all transitions. In total, eight rotational transitions, $\mathrm{N} \rightarrow \mathrm{N}+1$, were observed for each species in the frequency range of 259-310 GHz. Vibrational satellite lines were observed for ${ }^{64} \mathrm{Zn}^{79} \mathrm{Br}(\mathrm{v}=1$ and 2$),{ }^{64} \mathrm{Zn}^{81} \mathrm{Br}(\mathrm{v}=1,2$, and 3$)$, ${ }^{66} \mathrm{Zn}^{79} \mathrm{Br}(\mathrm{v}=1)$, and ${ }^{66} \mathrm{Zn}{ }^{81} \mathrm{Br}(\mathrm{v}=1)$.

Figure 2 presents spectra of the $N=53 \leftarrow 52$ rotational transition $(\mathrm{v}=0)$ for six isotopologues of $\mathrm{ZnBr}$. Each spectrum has a frequency break in order to show the spin-rotation doublets $(\mathrm{J}=52.5 \leftarrow 51.5$ and $53.5 \leftarrow 52.5)$, split by about $120 \mathrm{MHz}$. The top, middle, and bottom panels display the ${ }^{64} \mathrm{Zn}$, ${ }^{66} \mathrm{Zn}$, and ${ }^{68} \mathrm{Zn}$ species, respectively, with $\mathrm{Zn}^{81} \mathrm{Br}$ on the left and $\mathrm{Zn}^{79} \mathrm{Br}$ on the right. The varying line intensities reflect the zinc isotope abundances. Contaminant lines are present in the ${ }^{66} \mathrm{Zn}^{81} \mathrm{Br}$ and ${ }^{68} \mathrm{Zn}^{79} \mathrm{Br}$ data; the arrows identify the $\mathrm{ZnBr}$ features.

The transitions measured for ${ }^{67} \mathrm{Zn}^{79} \mathrm{Br}$ are presented in Table II. Five rotational transitions, $N \rightarrow N+1$, were recorded for this isotopologue. Each transition consists of fine structure doublets, which are further split into sextets by hyperfine interactions of the ${ }^{67} \mathrm{Zn}$ nucleus. Quantum number $\mathrm{F}$ labels the hyperfine lines, where $\mathbf{F}=\mathbf{J}+\mathbf{I}$. In the lower $J$ spin-rotation component, the lowest $F$ value transition is lowest in frequency, followed by the highest F value line, and then with decreasing $F$ to higher frequency. The two highest frequency components are blended together. In the higher spin-rotation component, the hyperfine transitions increase in frequency in sequence with the $F$ value. The two lowest frequency hyperfine components are blended in this case, creating a mirror image of the other sextet. This overall pattern is clearly seen in the $N=52 \leftarrow 51$ and $53 \leftarrow 52$ transitions, as shown in Table II. In other transitions, a few hyperfine components were also heavily blended with each other and could not reliably be included in the analysis.

Figure 3 displays the spectrum of the $N=54 \leftarrow 53$ transition of ${ }^{67} \mathrm{Zn}^{79} \mathrm{Br}$ near $291 \mathrm{GHz}$. The hyperfine pattern is displayed under the data, and the individual features are indicated by quantum number $F$. The spin-rotation doublets each exhibit a sextet pattern with two hyperfine lines closely blended in each set near the center of the pattern. For the higher frequency $\mathrm{J}=54.5 \leftarrow 53.5$ spin doublet, $\mathrm{F}$ increases with frequency, as mentioned; for the other doublet, the pattern wraps around, with the lowest $F$ value transition lying lowest in frequency, followed by the highest $\mathrm{F}$ component and then decreasing monotonically thereafter.

TABLE II. Observed transition frequencies for ${ }^{67} \mathrm{Zn}^{79} \mathrm{Br}: \mathrm{X}^{2} \Sigma^{+}(\mathrm{v}=0)$.

\begin{tabular}{|c|c|c|c|c|c|c|c|c|}
\hline$N^{\prime} \leftarrow N^{\prime \prime}$ & $\mathrm{J}^{\prime} \leftarrow \mathrm{J}^{\prime \prime}$ & $\mathrm{F}^{\prime} \leftarrow \mathrm{F}^{\prime \prime}$ & $v_{\text {obs }}$ & $v_{\mathrm{o}}-v_{\mathrm{c}}$ & $\mathrm{J}^{\prime} \leftarrow \mathrm{J}^{\prime \prime}$ & $\mathrm{F}^{\prime} \leftarrow \mathrm{F}^{\prime \prime}$ & $v_{\mathrm{obs}}$ & $v_{\mathrm{o}}-v_{\mathrm{c}}$ \\
\hline $48 \leftarrow 47$ & $47.5 \leftarrow 46.5$ & $\begin{array}{l}45 \leftarrow 44 \\
50 \leftarrow 49 \\
49 \leftarrow 48 \\
48 \leftarrow 47 \\
47 \leftarrow 46 \\
46 \leftarrow 45\end{array}$ & $\begin{array}{c}259197.664 \\
259200.011 \\
259202.652 \\
\ldots \\
\ldots \\
259208.322\end{array}$ & $\begin{array}{c}-0.051 \\
-0.037 \\
0.006 \\
\ldots \\
\ldots \\
-0.001\end{array}$ & $48.5 \leftarrow 47.5$ & $\begin{array}{l}46 \leftarrow 45 \\
47 \leftarrow 46 \\
48 \leftarrow 47 \\
49 \leftarrow 48 \\
50 \leftarrow 49 \\
51 \leftarrow 50\end{array}$ & $\begin{array}{l}259302.831 \\
259303.522 \\
259305.890 \\
259308.422 \\
259311.093 \\
259313.609\end{array}$ & $\begin{array}{l}0.017 \\
\ldots \\
-0.020 \\
-0.055 \\
0.022 \\
0.005\end{array}$ \\
\hline $52 \leftarrow 51$ & $51.5 \leftarrow 50.5$ & $\begin{array}{l}49 \leftarrow 48 \\
54 \leftarrow 53 \\
53 \leftarrow 52 \\
52 \leftarrow 51 \\
51 \leftarrow 50 \\
50 \leftarrow 49\end{array}$ & $\begin{array}{l}280709.926 \\
280712.038 \\
280714.325 \\
280716.468 \\
280718.270 \\
280718.567\end{array}$ & $\begin{array}{r}0.007 \\
0.063 \\
0.062 \\
0.009 \\
0.003 \\
-0.035\end{array}$ & $52.5 \leftarrow 51.5$ & $\begin{array}{l}50 \leftarrow 49 \\
51 \leftarrow 50 \\
52 \leftarrow 51 \\
53 \leftarrow 52 \\
54 \leftarrow 53 \\
55 \leftarrow 54\end{array}$ & $\begin{array}{l}280816.428 \\
280816.778 \\
280818.639 \\
280820.716 \\
280823.053 \\
280825.324\end{array}$ & $\begin{array}{r}-0.023 \\
-0.005 \\
0.053 \\
-0.063 \\
-0.010 \\
-0.009\end{array}$ \\
\hline $53 \leftarrow 52$ & $52.5 \leftarrow 51.5$ & $\begin{array}{l}50 \leftarrow 49 \\
55 \leftarrow 54 \\
54 \leftarrow 53 \\
53 \leftarrow 52 \\
52 \leftarrow 51 \\
51 \leftarrow 50\end{array}$ & $\begin{array}{l}286084.626 \\
286086.568 \\
286088.842 \\
286090.852 \\
286092.584 \\
286092.880\end{array}$ & $\begin{array}{r}0.061 \\
0.011 \\
0.066 \\
-0.038 \\
-0.017 \\
0.038\end{array}$ & $53.5 \leftarrow 52.5$ & $\begin{array}{l}51 \leftarrow 50 \\
52 \leftarrow 51 \\
53 \leftarrow 52 \\
54 \leftarrow 53 \\
55 \leftarrow 54 \\
56 \leftarrow 55\end{array}$ & $\begin{array}{l}286191.310 \\
286191.694 \\
286193.354 \\
286195.442 \\
286197.647 \\
286199.910\end{array}$ & $\begin{array}{r}-0.064 \\
0.083 \\
0.036 \\
0.014 \\
0.004 \\
0.056\end{array}$ \\
\hline $54 \leftarrow 53$ & $53.5 \leftarrow 52.5$ & $\begin{array}{l}51 \leftarrow 50 \\
56 \leftarrow 55 \\
55 \leftarrow 54 \\
54 \leftarrow 53 \\
53 \leftarrow 52 \\
52 \leftarrow 51\end{array}$ & $\begin{array}{c}291457.824 \\
291459.673 \\
291461.169 \\
291463.852 \\
291465.590 \\
\ldots\end{array}$ & $\begin{array}{c}0.029 \\
-0.054 \\
\ldots \\
-0.063 \\
0.056 \\
\ldots\end{array}$ & $54.5 \leftarrow 53.5$ & $\begin{array}{l}52 \leftarrow 51 \\
53 \leftarrow 52 \\
54 \leftarrow 53 \\
55 \leftarrow 54 \\
56 \leftarrow 55 \\
57 \leftarrow 56\end{array}$ & $\begin{array}{c}291564.878 \\
\ldots \\
291566.742 \\
291568.626 \\
291570.864 \\
291572.967\end{array}$ & $\begin{array}{l}0.025 \\
\ldots \\
\ldots \\
-0.029 \\
0.061 \\
0.010\end{array}$ \\
\hline $55 \leftarrow 54$ & $54.5 \leftarrow 53.5$ & $\begin{array}{l}52 \leftarrow 51 \\
57 \leftarrow 56 \\
56 \leftarrow 55 \\
55 \leftarrow 54 \\
54 \leftarrow 53 \\
53 \leftarrow 52\end{array}$ & $\begin{array}{l}296829.528 \\
296831.470 \\
296833.541 \\
296835.420 \\
296837.096 \\
296837.096\end{array}$ & $\begin{array}{r}-0.055 \\
0.014 \\
-0.003 \\
-0.087 \\
0.055 \\
-0.025\end{array}$ & $55.5 \leftarrow 54.5$ & $\begin{array}{l}53 \leftarrow 52 \\
54 \leftarrow 53 \\
55 \leftarrow 54 \\
56 \leftarrow 55 \\
57 \leftarrow 56 \\
58 \leftarrow 57\end{array}$ & $\begin{array}{l}296936.878 \\
296936.878 \\
296938.512 \\
296940.365 \\
296942.485 \\
296944.589\end{array}$ & $\begin{array}{r}0.014 \\
-0.064 \\
0.039 \\
-0.066 \\
-0.031 \\
-0.026\end{array}$ \\
\hline
\end{tabular}

${ }^{\mathrm{a}}$ In MHz. 


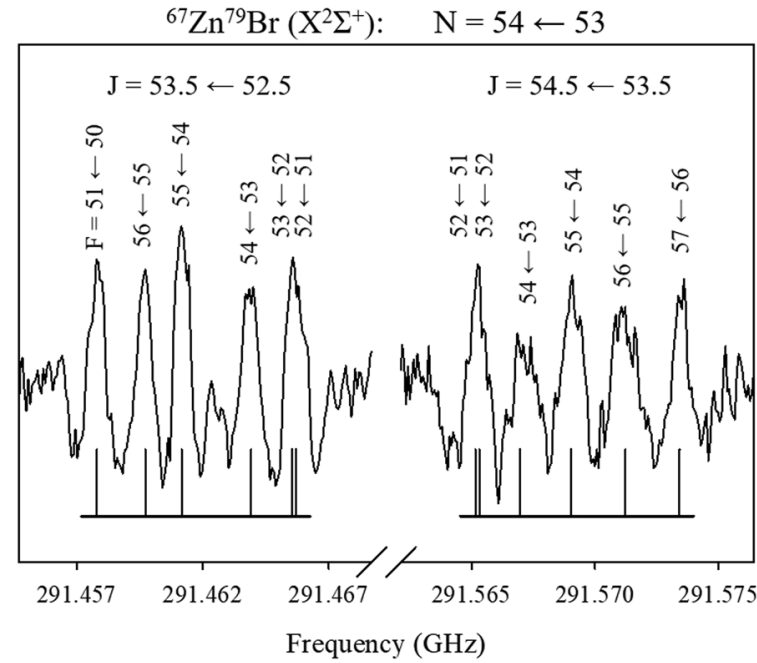

FIG. 3. Measured spectrum of the $N=54 \leftarrow 53$ rotational transition of ${ }^{67} \mathrm{Zn}{ }^{79} \mathrm{Br}$ near $291 \mathrm{GHz}$. The two spin-rotation doublets, labeled by $J$ and separated by a frequency break, each consist of a hyperfine sextet, arising from the ${ }^{67} \mathrm{Zn}$ nuclear spin of $I=5 / 2$. The pattern of the hyperfine lines, which are denoted by $F$, is shown under the spectrum. The $F=53 \leftarrow 52$ and $F=52 \leftarrow 51$ components are blended in each doublet. The sextet spectra were created from an average of $60,30 \mathrm{MHz}$ wide scans, each scan lasting $60 \mathrm{~s}$ in duration. Each spectrum has been truncated to $14 \mathrm{MHz}$.

\section{ANALYSIS}

The data were analyzed using a Hund's case $\left(b_{\beta J}\right)$ effective Hamiltonian comprised of rotation, spin-rotation, and zinc magnetic hyperfine terms (applicable only to ${ }^{67} \mathrm{ZnBr}$ )

$$
\hat{\mathrm{H}}_{\mathrm{eff}}=\hat{\mathrm{H}}_{\mathrm{rot}}+\hat{\mathrm{H}}_{\mathrm{sr}}+\hat{\mathrm{H}}_{\mathrm{mhf}(\mathrm{Zn})}
$$

Specific forms of these Hamiltonian terms are given in Ref. 34. Centrifugal distortion corrections are included in the three terms. The non-linear least squares fitting program SPFIT ${ }^{35}$ was used to fit the data. The seven isotopologues of $\mathrm{ZnBr}$ were fitted separately, as were the various vibrational states. The resulting spectroscopic constants are given in Table III $(\mathrm{v}=0)$ and Table IV ( $\mathrm{v}=1-3)$.

As shown in Table III, with the exception of ${ }^{67} \mathrm{ZnBr}$, all isotopologues of $\mathrm{ZnBr}$ were fit with a rotational constant (B), centrifugal distortion constant (D), spin-rotation parameter $(\gamma)$, and centrifugal distortion correction to spin-rotation $\left(\gamma_{\mathrm{D}}\right)$. The rms of the fits lies in the range $19-41 \mathrm{kHz}$. The same set of constants successfully fit the $\mathrm{v}=1-3$ states, as shown in Table IV. Here the rms of the fits was somewhat larger $(36-67 \mathrm{kHz})$ because of a lower signal-to-noise ratio. For ${ }^{67} \mathrm{Zn}^{79} \mathrm{Br}$, the hyperfine structure was successfully modeled with the Fermi contact term, $b_{\mathrm{F}}$, its centrifugal distortion correction, $b_{\mathrm{FD}}$, and the dipolar constant, $c$, resulting in an rms to the fit of $41 \mathrm{kHz}$ (see Table III). The parameter $c$ had to be fixed in the final analysis because it was defined only to a $2 \sigma$ uncertainty, not $3 \sigma$, as for all other constants. An attempt to fit the quadrupole parameter, eqQ, was not successful, and it was therefore not used in the final fit.

From molecular constants determined in the $\mathrm{v}=0-3$ states, equilibrium parameters were calculated using the following equations: 36

TABLE III. Spectroscopic constants for $\mathrm{ZnBr}: \mathrm{X}^{2} \Sigma^{+}(\mathrm{v}=0){ }^{\text {a }}$

\begin{tabular}{|c|c|c|c|c|c|c|c|}
\hline Parameter & ${ }^{64} \mathrm{Zn}^{79} \mathrm{Br}$ & ${ }^{64} \mathrm{Zn}^{81} \mathrm{Br}$ & ${ }^{66} \mathrm{Zn}^{79} \mathrm{Br}$ & ${ }^{66} \mathrm{Zn}^{81} \mathrm{Br}$ & ${ }^{67} \mathrm{Zn}^{79} \mathrm{Br}$ & ${ }^{68} \mathrm{Zn}^{79} \mathrm{Br}$ & ${ }^{68} \mathrm{Zn}^{81} \mathrm{Br}$ \\
\hline $\mathrm{B}_{0}$ & $2774.2898(41)$ & $2743.6679(41)$ & $2727.9180(41)$ & 2697.2954(41) & 2705.7114(25) & 2684.2292(41) & $2653.6069(41)$ \\
\hline $\mathrm{D} \times 10^{3}$ & $1.17091(74)$ & $1.14518(74)$ & $1.13218(74)$ & $1.10690(74)$ & $1.11384(44)$ & $1.09601(74)$ & $1.07133(74)$ \\
\hline$\gamma$ & $121.95(86)$ & $120.16(83)$ & $120.40(86)$ & $118.53(86)$ & $118.64(52)$ & $118.08(86)$ & $116.58(86)$ \\
\hline $\begin{array}{l}\gamma_{\mathrm{D}} \times 10^{4} \\
b_{\mathrm{F}}(\mathrm{Zn})\end{array}$ & $-4.5(1.1)$ & $-3.94(99)$ & $-5.0(1.1)$ & $-4.3(1.1)$ & $\begin{array}{c}-3.97(62) \\
1133.9(5.4)\end{array}$ & $-4.3(1.1)$ & $-4.1(1.1)$ \\
\hline$b_{\mathrm{FD}}(\mathrm{Zn})$ & & & & & $0.00066(26)$ & & \\
\hline$c(\mathrm{Zn})$ & & & & & $21.06^{\mathrm{b}}$ & & \\
\hline $\mathrm{rms}$ & 0.025 & 0.024 & 0.030 & 0.019 & 0.041 & 0.041 & 0.030 \\
\hline
\end{tabular}

${ }^{\mathrm{a}}$ Parameters in $\mathrm{MHz}$; quoted uncertainties are $3 \sigma$.

${ }^{\mathrm{b}}$ Held fixed.

TABLE IV. Spectroscopic Constants for $\mathrm{ZnBr}: \mathrm{X}^{2} \Sigma^{+}(\mathrm{v}=1-3)$. $^{\mathrm{a}}$

\begin{tabular}{|c|c|c|c|c|c|c|c|}
\hline \multirow[b]{2}{*}{ Parameter } & \multicolumn{4}{|c|}{$\mathrm{v}=1$} & \multicolumn{2}{|c|}{$\mathrm{v}=2$} & \multirow{2}{*}{$\frac{\mathrm{v}=3}{{ }^{64} \mathrm{Zn}^{81} \mathrm{Br}}$} \\
\hline & ${ }^{64} \mathrm{Zn}^{79} \mathrm{Br}$ & ${ }^{64} \mathrm{Zn}^{81} \mathrm{Br}$ & ${ }^{66} \mathrm{Zn}^{79} \mathrm{Br}$ & ${ }^{66} \mathrm{Zn}^{81} \mathrm{Br}$ & ${ }^{64} \mathrm{Zn}^{79} \mathrm{Br}$ & ${ }^{64} \mathrm{Zn}^{81} \mathrm{Br}$ & \\
\hline $\mathrm{B}_{v}$ & 2761.6274(41) & $2731.2158(44)$ & $2715.5747(41)$ & $2685.1549(44)$ & $2748.9526(43)$ & $2718.7454(46)$ & $2706.2680(53)$ \\
\hline $\mathrm{D}_{v} \times 10^{3}$ & $1.17296(74)$ & $1.14729(78)$ & $1.13453(74)^{\prime}$ & $1.10839(78)$ & $1.17553(76)$ & $1.14887(84)$ & $1.15240(99)$ \\
\hline$\gamma$ & $118.10(86)$ & 116.61(91) & $116.17(86)$ & $115.23(91)$ & $113.68(88)$ & $112.68(96)$ & 108.8(1.1) \\
\hline$\gamma_{D} \times 10^{4}$ & $-4.9(1.1)$ & $-4.6(1.1)$ & $-4.7(1.1)$ & $-5.1(1.1)$ & $-4.7(1.1)$ & $-5.0(1.2)$ & $-5.5(1.4)$ \\
\hline rms & 0.043 & 0.045 & 0.038 & 0.047 & 0.036 & 0.042 & 0.067 \\
\hline
\end{tabular}

aparameters in MHz; quoted uncertainties are $3 \sigma$. 
TABLE V. Equilibrium parameters for $\mathrm{ZnBr}\left(\mathrm{X}^{2} \Sigma^{+}\right)$. $^{\text {a }}$

\begin{tabular}{lcccc}
\hline \hline Parameter & ${ }^{64} \mathrm{Zn}^{79} \mathrm{Br}$ & ${ }^{64} \mathrm{Zn}^{81} \mathrm{Br}$ & ${ }^{66} \mathrm{Zn}^{79} \mathrm{Br}$ & ${ }^{66} \mathrm{Zn}^{81} \mathrm{Br}$ \\
\hline $\mathrm{B}_{e}(\mathrm{MHz})$ & $2780.626(18)$ & $2749.908(28)$ & $2734.0897(22)$ & $2703.3657(22)$ \\
$\alpha_{e}(\mathrm{MHz})$ & $12.669(11)$ & $12.467(12)$ & $12.3433(20)$ & $12.1405(21)$ \\
$\mathrm{D}_{e} \times 10^{3}(\mathrm{MHz})$ & $1.16967(77)$ & $1.1438(20)$ & $1.1310050(40)$ & $1.1061550(40)$ \\
$\beta_{e} \times 10^{6}(\mathrm{MHz})$ & $2.31(45)$ & $2.32(85)$ & $2.3500(35)$ & $1.4900(36)$ \\
$\gamma_{e}(\mathrm{MHz})$ & $124.11(84)$ & $122.15(39)$ & $122.52(46)$ & $120.18(46)$ \\
$\gamma_{e}(\mathrm{MHz})$ & $-4.14(49)$ & $-3.79(17)$ & $-4.23(41)$ & $-3.30(42)$ \\
$\omega_{e}\left(\mathrm{~cm}^{-1}\right)$ & 286 & 284 & 284 & 282 \\
$\omega_{e} x_{e}\left(\mathrm{~cm}^{-1}\right)$ & 1.04 & 1.03 & 1.02 & 1.01 \\
$\mathrm{D}_{\mathrm{E}}(\mathrm{eV})$ & 2.45 & 2.45 & 2.45 & 2.45 \\
\hline $\mathrm{r}_{\mathrm{e}}(\AA)$ & $2.26848(90)$ & $2.2685(14)$ & $2.26848(11)$ & $2.26848(11)$ \\
\hline \hline
\end{tabular}

${ }^{\mathrm{a}}$ Quoted uncertainties are $3 \sigma$.

$$
\begin{aligned}
\mathrm{B}_{v} & =\mathrm{B}_{e}-\alpha_{e}(\mathrm{v}+1 / 2), \\
\mathrm{D}_{v} & =\mathrm{D}_{e}+\beta_{e}(\mathrm{v}+1 / 2), \\
\gamma_{v} & =\gamma_{e}+\gamma_{e}^{\prime}(\mathrm{v}+1 / 2) .
\end{aligned}
$$

A least-squares analysis was performed to determine the constants for ${ }^{64} \mathrm{Zn}^{79} \mathrm{Br}$ and ${ }^{64} \mathrm{Zn}^{81} \mathrm{Br}$, as more than one vibrationally excited state was observed. For the other isotopologues, a simple algebraic solution was found. The resulting equilibrium constants are given in Table $V$. The vibrational frequency $\left(\omega_{e}\right)$, anharmonicity constant $\left(\omega_{e} x_{e}\right)$, and dissociation energy $\left(D_{E}\right)$ were then calculated using

$$
\begin{aligned}
\omega_{e} & =\left(4 \mathrm{~B}_{e}{ }^{3} / \mathrm{D}_{e}\right)^{1 / 2}, \\
\omega_{e} x_{e} & =\mathrm{B}_{e}\left(\alpha_{e} \omega_{e} / 6 \mathrm{~B}_{e}^{2}+1\right)^{2}, \\
\mathrm{D}_{\mathrm{E}} & =\left(\omega_{e}{ }^{2} / 4 \omega_{e} x_{e}\right) .
\end{aligned}
$$

The resulting constants, as well as the equilibrium bond length calculated to be $2.26848(90) \AA$, are also given in

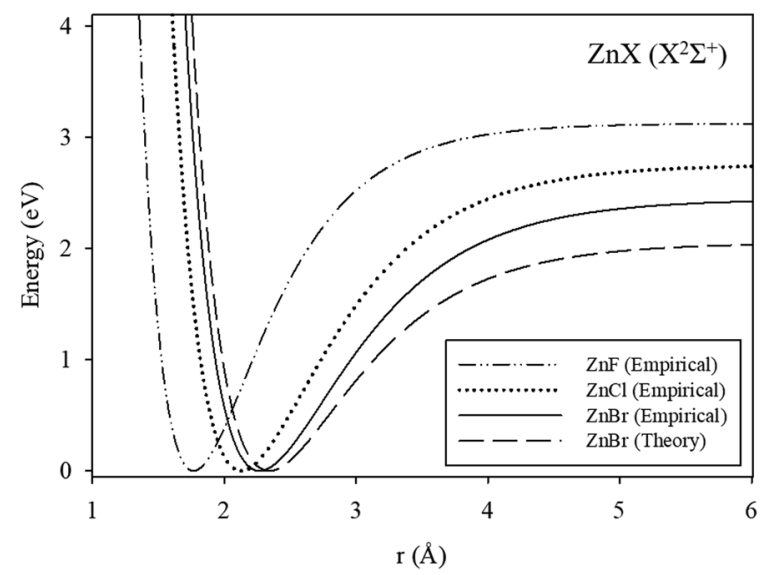

FIG. 4. Morse potential curves generated empirically from experimental equilibrium parameters of $\mathrm{ZnF}^{19}$ (dotted-dashed line), $\mathrm{ZnCl}^{15}$ (dotted line), and $\mathrm{ZnBr}$ (solid line), as well as the theoretical curve for zinc bromide from Ref. 24 (dashed line). The theoretical and empirical curves for $\mathrm{ZnBr}$ are in reasonable agreement. The curves show the expected increase in the bond length and well anharmonicity from $\mathrm{ZnF}$ to $\mathrm{ZnBr}$.
Table V. From these equations, a Morse potential (plotted in Fig. 4) was made using the following expression, where $k_{e}=\omega_{e}^{2} \mu$ :

$$
\mathrm{V}(\mathrm{r})=\mathrm{D}_{e}\left(1-\mathrm{e}^{-\sqrt{k_{e} / 2 \mathrm{D}_{e}}\left(\mathrm{r}-\mathrm{r}_{\mathrm{e}}\right)}\right)^{2}
$$

\section{DISCUSSION}

This study demonstrates that $\mathrm{ZnBr}$ has a ${ }^{2} \Sigma^{+}$ground state, as indicated by previous optical data and predicted by theory. ${ }^{20,24}$ It therefore follows the pattern established from $\mathrm{ZnF}$ and $\mathrm{ZnCl}{ }^{19,15}$ The equilibrium bond length, $r_{e}=2.26848(90) \AA$, however, is shorter than the best theoretical value of $2.341 \AA .{ }^{24}$ It is also significantly shorter than the $\mathrm{Zn}-\mathrm{Br}$ bond length of 2.42(1) $\AA$, derived from the $\mathrm{ZnBr}_{2}$ crystal structure. ${ }^{37}$ Bond lengths have been established for four other $3 d$ diatomic bromides: $\operatorname{ScBr}\left(\mathrm{X}^{1} \Sigma\right), \operatorname{TiBr}\left(\mathrm{X}^{4} \Phi_{\mathrm{r}}\right), \operatorname{CuBr}\left(\mathrm{X}^{1} \Sigma\right)$, and $\operatorname{NiBr}\left(X^{2} \Pi_{i}\right) \cdot{ }^{26-29,31} \mathrm{TiBr}$ has the longest bond length of the series with $r_{e}=2.411 \AA$, closely followed by $\operatorname{ScBr}\left(r_{e}=2.381\right.$ $\AA)$, whereas $\mathrm{CuBr}$ has the shortest $\left(\mathrm{r}_{\mathrm{e}}=2.173 \AA\right.$ ), with a similar value for $\mathrm{NiBr}\left(\mathrm{r}_{0}=2.178 \AA\right)$.

The bond lengths for the $3 d$ bromides appear to follow the trend established by the corresponding chlorides, as plotted in Fig. 5. Here experimental bond lengths of the chlorides ${ }^{15,38-46}$ and the known bromides ${ }^{26-29,31}$ are given as a function of the $3 d$ metal. The bond lengths are $\mathrm{r}_{\mathrm{e}}$, except for the case of $\mathrm{VCl}, \mathrm{FeCl}, \mathrm{NiCl}$, and $\mathrm{NiBr}$, where it is $\mathrm{r}_{0}$. Unfortunately, the bond distances have only been measured accurately for a few of the bromides, as mentioned, while the chloride series is complete. Nevertheless, the variation in bromide bond lengths closely resembles that of the chlorides. The scandium compounds have one of the longest values of the $3 d$ series, with a small increase of $\sim 0.03 \AA$ at titanium. The bond lengths then decrease by $\sim 0.2 \AA$ going to copper and nickel. They subsequently increase at zinc by almost $0.1 \AA$. The negligible change in the bond length from $\mathrm{Ni}$ to $\mathrm{Cu}$ for both sets of halides suggests that the additional electron adds to a non-bonding $\pi$ orbital. Conversely, the distinct increase from $\mathrm{Cu}$ to $\mathrm{Zn}$ is a likely result of the addition to an anti-bonding (primarily $\sigma$ ) orbital. 


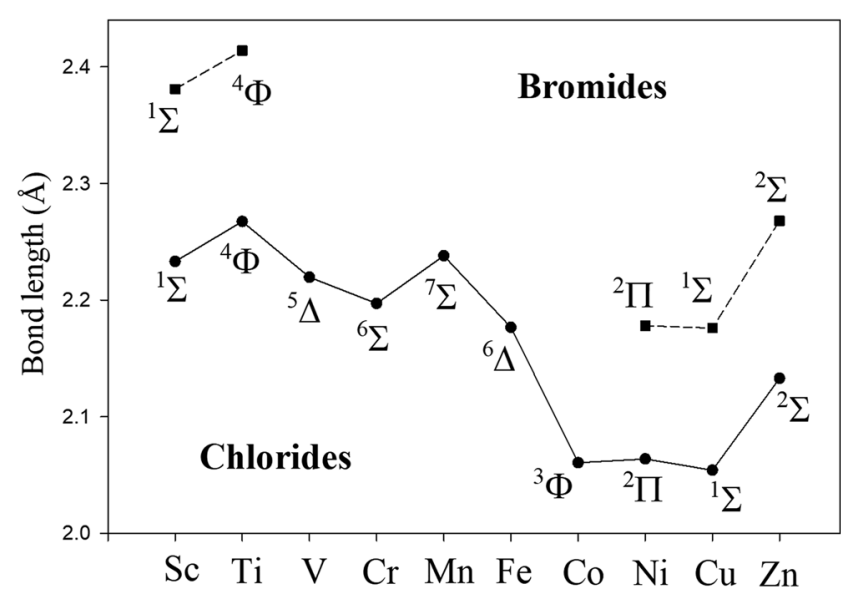

FIG. 5. A plot of the bond lengths as a function of $3 d$ metals for the chloride and bromide series. Experimental bond lengths have been measured for all chlorides, but only for five bromides $(\mathrm{ScBr}, \mathrm{TiBr}, \mathrm{NiBr}, \mathrm{CuBr}$, and $\mathrm{ZnBr}$ ). Bond lengths are typically $r_{e}$, except in the cases where only $r_{0}$ values are available $(\mathrm{VCl}, \mathrm{FeCl}$, $\mathrm{NiCl}$, and $\mathrm{NiBr}$ ). The trend established by the chlorides appears to be replicated in the bromides. The titanium halide has the longest bond length of the $3 d$ series, but only slightly longer $(\sim 0.03 \AA)$ than that of the scandium species. The bond length shortens by $\sim 0.2 \AA$ for copper and nickel, and then increases by almost $0.1 \AA$ at zinc.

The calculated values of the vibrational constants found in this work are $\omega_{e}=286 \mathrm{~cm}^{-1}$ and $\omega_{e} x_{e}=1.04 \mathrm{~cm}^{-1}$. In comparison, the best theoretical value ${ }^{24}$ is $\omega_{e} \approx 267.2 \mathrm{~cm}^{-1}$, roughly similar. The past experimental gas-phase measurement ${ }^{20}$ of this parameter was $\omega_{e} \approx 319 \mathrm{~cm}^{-1}$, closer to our value than the Raman estimate ${ }^{21}$ of $\omega_{e} \approx 198 \mathrm{~cm}^{-1}$. This work here resolves the 30-year discrepancy between the reported experimental numbers for $\omega_{e}$ and confirms the theoretical estimate as the most accurate value prior to this study.

The dissociation energy, $\mathrm{D}_{\mathrm{E}}$, determined here from a simple Morse potential model is $\sim 2.448 \mathrm{eV}$ [Eq. (7)]. The most accurate theory value is $\sim 2.049 \mathrm{eV},{ }^{24}$ in reasonable agreement. As shown in Fig. 4, the empirical Morse potential curve and that established by multireference configuration interaction (MRCI) calculations are qualitatively similar. The potential curves for $\mathrm{ZnF}^{19}$ and $\mathrm{ZnCl},{ }^{15}$ derived from equilibrium parameters and a Morse potential, are also displayed in Fig. 4. As expected, there is an increase in the bond length and a decrease in the dissociation energy from $\mathrm{ZnF}$ to $\mathrm{ZnBr}$.

The equilibrium spin-rotation parameter, $\gamma_{e}$, for the known zinc halides are 150,126 , and $122 \mathrm{MHz}$ for $\mathrm{ZnF}$, $\mathrm{ZnCl}$, and $\mathrm{ZnBr}$, respectively. For these three species, $\gamma_{e} / \mathrm{B}_{e}$ is $\sim 0.014,0.026$, and 0.045 , indicating that the spin-rotation constant does not scale directly with mass, as would be expected to first order. Second-order spin-orbit coupling clearly plays an important role here in determining the value of $\gamma \cdot{ }^{47}$ The nearest perturber influencing this interaction may be the $A^{2} \Pi$ state, which results from the promotion of the unpaired $\sigma$ electron to the nearest $\pi$ orbital. Elmoussaoui et al. ${ }^{24,25}$ calculate that this state drops in energy from $\sim 38000 \mathrm{~cm}^{-1}$ in $\mathrm{ZnF}$ to $\sim 33000$ and $\sim 32000 \mathrm{~cm}^{-1}$ for $\mathrm{ZnCl}$ and $\mathrm{ZnBr}$. Furthermore, there could be other low-lying electronic states that are coupled to the ground ${ }^{2} \Sigma$ state through $\mathbf{H}_{\text {so }}$ operator, contributing to the value of $\gamma$. Theory suggests there are 19 doublet and quartet excited states in $\mathrm{ZnBr}$ lying less than $59000 \mathrm{~cm}^{-1}$ in energy. ${ }^{24} \mathrm{New}$ experimental electronic measurements of the zinc halides are clearly needed to confirm their excited state manifolds.

The ${ }^{67} \mathrm{Zn},{ }^{79} \mathrm{Br}$, and ${ }^{81} \mathrm{Br}$ nuclei all have nuclear spins, as mentioned, with magnetic moments of 0.87, 2.1, and $2.3 \mathrm{Bohr}$ magnetons, respectively. ${ }^{48}$ In ${ }^{67} \mathrm{Zn}^{79} \mathrm{Br}$, however, the observed hyperfine pattern clearly arises from the ${ }^{67} \mathrm{Zn}$ spin, indicating that the unpaired electron resides primarily on the zinc nucleus, likely in the $15 \sigma$ orbital chiefly $4 s$ in character. The Fermi contact constant $\left(b_{\mathrm{F}}\right)$ can give an estimate of the scharacter of the orbital of the unpaired electron by comparing it with the atomic value for the ${ }^{67} \mathrm{Zn}^{+}$nucleus. As discussed by Flory et al., ${ }^{19}$ a gas-phase value of the Fermi contact term for this nucleus does not exist, but a value of $1425.6 \mathrm{MHz}$ has been established in calcite. ${ }^{49}$ Using this number, $b_{\mathrm{F}}\left({ }^{67} \mathrm{ZnBr}\right) / b_{\mathrm{F}}$ $\left({ }^{67} \mathrm{Zn}\right) \approx 0.80$, suggesting the orbital of the unpaired electron is $\sim 80 \%$ s character. Alternatively, calculations done by Koh and Miller ${ }^{50}$ using the Roothan-Hartree-Fock method predict the Fermi contact term of $\mathrm{Zn}^{+}$to be $1683.96 \mathrm{MHz}$. In this case, the percent s character is $\sim 69 \%$ for $\mathrm{ZnBr}$.

The $s$ character of the orbital containing the unpaired electron has also been calculated for $\mathrm{ZnF}$ and $\mathrm{ZnCl} \cdot{ }^{19,15}$ For comparison, these values are listed in Table VI, along with those for $\mathrm{ZnBr}$. Independent of the chosen value of the atomic Fermi contact constant for the ${ }^{67} \mathrm{Zn}^{+}$nucleus, the trend is clear. The greatest $s$ contribution to the orbital of the unpaired electron is found for $\mathrm{ZnF}$, followed by $\mathrm{ZnCl}$, and then $\mathrm{ZnBr}$. Therefore, the ionic character of the metal halide bond decreases down the halogen column, as predicted by theory. ${ }^{25}$ This decrease is thought to arise from the decline in the electronegativity of the halide atom from fluorine to bromine.

The dipolar constant, $c$, indicates the non-spherical or angular character of the orbital with the unpaired electron, namely, the $\pi$ and $\delta$ contributions. There are no experimental or computational values available for the atomic ${ }^{67} \mathrm{Zn}^{+}$dipolar term. Therefore, it is difficult to evaluate the angular part of the orbital with any reliability. However, an estimate of the atomic ${ }^{67} \mathrm{Zn}^{+}$dipolar term can be made by the Goudsmit method $^{51,52}$ of analyzing nuclear magnetic moments; see Flory et al. $^{19}$ This method yields a value of the dipolar term of $\sim 500 \mathrm{MHz}$, suggesting the non-spherical character in the

TABLE VI. Fermi contact values for $\mathrm{ZnF}, \mathrm{ZnCl}$, and $\mathrm{ZnBr}{ }^{2}$

\begin{tabular}{lccc}
\hline \hline Parameter & $\mathrm{ZnF}^{\mathrm{b}}$ & $\mathrm{ZnCl}^{\mathrm{c}}$ & $\mathrm{ZnBr}$ \\
\hline$b_{\mathrm{F}}(\mathrm{Zn})$ & $1291.4(1.6)$ & $1192.9(2.6)$ & $1133.9(1.8)$ \\
$\% \mathrm{Zn}(4 \mathrm{~s})$ & $90,{ }^{\mathrm{d}} 7^{\mathrm{e}}$ & $83,{ }^{\mathrm{d}}{ }^{\mathrm{e}}$ & $80,{ }^{\mathrm{d}} \mathbf{6 9}$ \\
\hline \hline
\end{tabular}

${ }^{\mathrm{a}}$ In MHz.

${ }^{\mathrm{b}}$ Reference 19 .

${ }^{\mathrm{c}}$ Reference 15 .

${ }^{\mathrm{d}}$ Using the estimate for $b_{\mathrm{F}}\left({ }^{67} \mathrm{Zn}^{+}\right)$derived in calcite; see the text.

${ }^{\mathrm{e}}$ Using the theoretical estimate for $b_{\mathrm{F}}\left({ }^{67} \mathrm{Zn}^{+}\right)$; see the text. 
orbital of the unpaired electron in $\mathrm{ZnBr}$ is $\sim 4 \%$. This result suggests that the total orbital contribution from the bromine atom in $\mathrm{ZnBr}$ is $\sim 16 \%$.

\section{CONCLUSIONS}

These measurements constitute the first in-depth spectroscopic study of the $\mathrm{ZnBr}$ radical. From this work, molecular properties for zinc bromide have been derived that allow direct comparison with the other zinc halides that have been investigated spectroscopically. $\mathrm{ZnBr}$ appears to be less ionic than either $\mathrm{ZnCl}$ or $\mathrm{ZnF}$, with more bonding contribution from the bromine atom, in agreement with theoretical predictions. In addition, the bond length in $\mathrm{ZnBr}$ appears to increase significantly from neighboring $\mathrm{CuBr}$, in a trend also seen in the $3 d$ chlorides. This study helps to benchmark recent theoretical calculations for zinc bromide. It also lays the foundation for future optical and infrared measurements of this radical.

\section{SUPPLEMENTARY MATERIAL}

See supplementary material for the complete list of measured transition frequencies for ${ }^{64} \mathrm{Zn}^{79} \mathrm{Br},{ }^{64} \mathrm{Zn}^{81} \mathrm{Br},{ }^{66} \mathrm{Zn}^{79} \mathrm{Br}$, ${ }^{66} \mathrm{Zn}^{81} \mathrm{Br},{ }^{68} \mathrm{Zn}^{79} \mathrm{Br}$, and ${ }^{68} \mathrm{Zn}{ }^{81} \mathrm{Br}\left(\mathrm{X}^{2} \Sigma^{+}\right)$for the $\mathrm{v}=0-3$ vibrational states.

\section{ACKNOWLEDGMENTS}

The authors would like to thank Dr. DeWayne Halfen for helpful discussions. This research was supported by NSF Grant No. CHE-1565765.

\section{REFERENCES}

${ }^{1}$ D. M. M. Rohe and H. U. Wolf, Zinc Compounds, Ullmann's Encyclopedia of Industrial Chemistry (Wiley-VCH, Weinheim, 2000).

${ }^{2}$ H. O. House, D. S. Crumrine, A. Y. Teranishi, and H. D. Olmstead, J. Am. Chem. Soc. 95, 3310 (1973).

${ }^{3}$ S. Kim, Y. J. Kim, and K. H. Ahn, Tetrahedron Lett. 24, 3369 (1983).

${ }^{4}$ O. K. Srivastava and E. A. Secco, Can. J. Chem. 45, 585 (1967).

${ }^{5}$ J. Sun, S.-I. Fujita, F. Zhao, and M. Arai, Green Chem. 6, 613 (2004).

${ }^{6}$ Y. Q. Tu, C. A. Fan, S. K. Ren, and A. S. C. Chan, J. Chem. Soc., Perkin Trans. 1 2000, 3791.

${ }^{7}$ A. Keivanloo, M. Bakherad, B. Bahramian, and S. Baratnia, Tetrahedron Lett. 52, 1498 (2011).

${ }^{8}$ D. Linden and T. Reddy, Handbook of Batteries, 3rd ed. (McGraw-Hill, New York, 2002).

${ }^{9}$ P. M. Hoobin, K. J. Cathro, and J. O. Niere, J. Appl. Electrochem. 19, 943 (1989).

${ }^{10}$ E. Manla, A. Nasiri, C. H. Rentel, and M. Hughes, IEEE Trans. Ind. Electron. 57, 624 (2010).

${ }^{11}$ W. I. Jang, J. W. Lee, Y. M. Baek, and O. O. Park, Macromol. Res. 24, 276 (2016).

${ }^{12}$ S. Suresh, T. Kesavan, Y. Munaiah, I. Arulraj, S. Dheenadayalan, and P. Ragupathy, RSC Adv. 4, 37947 (2014).

${ }^{13}$ M. B. Sureshkumar, S. Sharma, A. B. Darji, P. M. Shah, and N. R. Shah, Optica pura y aplicada 27, 198 (1994)

${ }^{14}$ S. D. Cornell, Phys. Rev. 54, 341 (1938)
${ }^{15}$ E. D. Tenenbaum, M. A. Flory, R. L. Pulliam, and L. M. Ziurys, J. Mol. Spectrosc. 244, 153 (2007).

${ }^{16}$ A. I. Boldyrev and J. Simons, Mol. Phys. 92, 365 (1997)

${ }^{17}$ I. S. K. Kerkines, A. Mavridis, and P. A. Karipidis, J. Phys. Chem. A 110, 10899 (2006).

${ }^{18}$ L. B. Knight, Jr., A. Mouchet, W. T. Beaudry, and M. Duncan, Magn. Reson. 32, 383 (1978).

${ }^{19}$ M. A. Flory, S. K. McLamarrah, and L. M. Ziurys, J. Chem. Phys. 125, 194304 (2006).

${ }^{20}$ R. K. Gosavi, G. Greig, P. J. Young, and O. P. Strausz, J. Chem. Phys. 54, 983 (1971).

${ }^{21}$ A. Givan and A. Loewenschuss, J. Mol. Spectrosc. 78, 299 (1982).

${ }^{22}$ G. A. Bowmaker and P. Schwerdtfeger, J. Mol. Struct.: THEOCHEM 205, 295 (1990).

${ }^{23}$ M.-S. Liao, Q.-E. Zhang, and W. H. E. Schwarz, Inorg. Chem. 34, 5597 (1995).

${ }^{24}$ S. Elmoussaoui and M. Korek, Comput. Theor. Chem. 1068, 42 (2015).

${ }^{25}$ S. Elmoussaoui, N. El-Kork, and M. Korek, Comput. Theor. Chem. 1090, 94 (2016).

${ }^{26}$ W. Lin, C. J. Evans, and M. C. L. Gerry, Phys. Chem. Chem. Phys. 2, 43 (2000).

${ }^{27}$ E. Lowry Manson, F. C. De Lucia, and W. Gordy, J. Chem. Phys. 63, 2724 (1975).

${ }^{28}$ R. J. Low, T. D. Varberg, J. P. Connelly, A. R. Auty, B. J. Howard, and J. M. Brown, J. Mol. Spectrosc. 161, 499 (1993).

${ }^{29}$ E. Yamazaki, T. Okabayashi, and M. Tanimoto, J. Chem. Phys. 121, 162 (2004).

${ }^{30}$ Y. Xia, Z. Liao, M. Yang, M.-C. Chan, and A. S.-C. Cheung, Chem. Phys. Lett. 527, 7 (2012).

${ }^{31}$ A. G. Adam, W. S. Hopkins, W. Sha, and D. W. Tokaryk, J. Mol. Spectrosc. 236, 42 (2006).

32 J. W.-H. Leung, X. Wang, and A. S.-C. Cheung, J. Chem. Phys. 117, 3694 (2002).

${ }^{33}$ L. M. Ziurys, W. L. Barclay, Jr., M. A. Anderson, D. A. Fletcher, and J. W. Lamb, Rev. Sci. Instrum. 65, 1517 (1994).

${ }^{34} \mathrm{~J}$. Brown and A. Carrington, Rotational Spectroscopy of Diatomic Molecules (Cambridge University Press, United Kingdom, 2003).

${ }^{35}$ H. M. Pickett, J. Mol. Spectrosc. 148, 371 (1991).

${ }^{36}$ W. Gordy and R. L. Cook, Microwave Molecular Spectra (Wiley, New York, 1984).

${ }^{37}$ C. Chieh and M. A. White, Z. Kristallogr. - Cryst. Mater. 166, 189 (1984).

${ }^{38}$ W. Lin, S. A. Beaton, C. J. Evans, and M. C. L. Gerry, J. Mol. Spectrosc. 199, 275 (2000).

${ }^{39}$ A. Maeda, T. Hirao, P. F. Bernath, and T. Amano, J. Mol. Spectrosc. 210, 250 (2001).

${ }^{40}$ D. T. Halfen, L. M. Ziurys, and J. M. Brown, J. Chem. Phys. 130, 164301 (2009).

${ }^{41}$ T. Oike, T. Okabayashi, and M. Tanimoto, J. Chem. Phys. 109, 3501 (1998).

${ }^{42}$ D. T. Halfen and L. M. Ziurys, J. Chem. Phys. 122, 054309 (2005).

${ }^{43}$ M. D. Allen, B. Z. Li, and L. M. Ziurys, Chem. Phys. Lett. 270, 517 (1997).

${ }^{44}$ M. A. Flory, D. T. Halfen, and L. M. Ziurys, J. Chem. Phys. 121, 8385 (2004).

${ }^{45}$ E. Yamazaki, T. Okabayashi, and M. Tonimoto, Astrophys. J. 551, L199 (2001).

${ }^{46}$ E. L. Manson, F. C. De Lucia, and W. Gordy, J. Chem. Phys. 62, 1040 (1975).

${ }^{47}$ J. M. Brown, E. A. Colbourn, J. K. G. Watson, and F. D. Wayne, J. Mol, Spectrosc. 74, 294 (1979).

${ }^{48}$ C. H. Townes and A. L. Schawlow, Microwave Spectroscopy (Dover Publications, New York, 1975).

${ }^{49}$ F. F. Popescu and V. V. Grecu, Solid State Commun. 13, 749 (1973).

${ }^{50}$ A. K. Koh and D. J. Miller, At. Data Nucl. Data Tables 33, 235 (1985).

${ }^{51}$ S. Goudsmit, Phys. Rev. 43, 636 (1933).

${ }^{52}$ W. Weltner, Jr., Magnetic Atoms and Molecules (Scientific and Academic Editions, New York, 1983). 